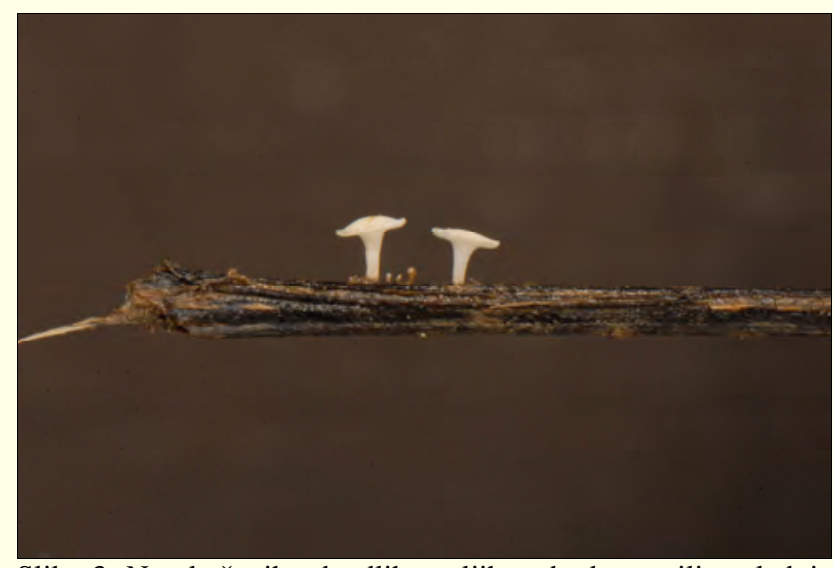

Slika 3: Na okuženih odpadlih pecljih se bodo razvili naslednje leto od pomladi do jeseni apoteciji glive Hymenoscyphus albidus, ki je teleomorf glive Chalara fraxinea.

\title{
Mraznica je poškodovala veliki jesen pri Radljah ob Dravi
}

\author{
Nikica OGRIS $^{1 *}$, Gorazd MLINŠEK ${ }^{2}$
}

Na Planini pri Radljah ob Dravi (Pahernikovi gozdovi) smo na površini 0,3 ha v sestoju velikega jesena (Fraxinus excelsior), ki je bil posajen pred 25 leti, zabeležili srednje močno poškodovanost jesena zaradi mraznice (Armillaria sp.). Mraznica je kot primarni parazit okužila korenine, koreničnik in spodnji del jesenovih debel na bogatem in vlažnem rastišču. Mraznica je samo $v$ eni rastni sezoni povzročila tudi do 50 cm dolge nekroze v skorji. Nekroza se je jezikasto širila iz korenin navzgor po deblu. Ko smo z nožem odstranili zunanji del skorje, smo v skorji in kambiju opazili podgobje bele do bež barve in pahljačastega videza (slika 1). Takšno podgobje je značilno za glivo mraznico ali štorovko. Najverjetneje gre za sivorumeno mraznico (A. mellea), ki je priložnostno zelo agresiven primarni parazit in kuži številne listavce, redkeje iglavce. Nekroza je bila v vsej dolžini sveža, t. j. odmiranje skorje in kambija se je razvilo letos. Pod nekrozo je les trohnel.

Z gotovostjo lahko predvidimo, da bodo poškodovana drevesa še naprej trohnela, slabše bodo priraščala in verjetno bodo $\mathrm{v}$ daljšem časovnem razdobju shirala in odmrla. Z veliko verjetnostjo lahko napovemo, da se bodo $\mathrm{v}$ omenjenem sestoju poškodbe zaradi mraznice širile na ostala drevesa vseh vrst in ne samo velikega jesena. Hitrost širjenja bo odvisna predvsem od zunanjih stresnih dejavnikov, ki bodo $\mathrm{v}$ prihodnosti prizadeli sestoj. Okužba se bo širila približno v koncentričnih krogih iz centrov, kjer so danes okužena drevesa.

Pri ukrepanju imamo na voljo dve možnosti. (1) Okužena drevesa posekamo. Iz sestoja odstranimo tudi panje skupaj s koreninami, v kolikor je to ekonomsko upravičeno in mogoče. Če odstranimo panje okuženih dreves, preprečimo hitro širjenje bolezni na sosednja drevesa. Mraznica se širi na dva načina: z rizomorfi in z bazidiosporami. Rizomorfi se razraščajo od okuženega panja in korenin v tleh in povzročajo okužbe zdravih korenin sosednjih dreves. Iz micelija $\mathrm{v}$ odmirajoči skorji in v kambiju prodirajo hife v les in v njem povzročajo belo trohnobo. Mraznica se $\mathrm{v}$ panjih in koreninah prehranjuje saprofitsko in dobro prehranjena lahko oblikuje veliko število rizomorfov z veliko infekcijsko sposobnostjo. Mraznica z veliko količino hrane (ki jo predstavlja panj in koreninski sistem odmrlega ali požaganega drevesa) ima bolj izražen patogeni značaj kot oslabljena mraznica, z manjšo količino razpoložljive hrane. Bazidiospore se oblikujejo na lističih trosnjakov, ki se pojavijo jeseni ob ali na koreničniku okuženega ali odmrlega drevesa. Bazidiospore lahko okužujejo drevo samo skozi rane, zato predstavlja vsaka rana, ki nastane na skorji, potencialno vstopno mesto za okužbo z mraznico. (2) Gozdnogojitveni ukrepi: v poškodovanem sestoju postopno zamenjamo okužena drevesa z bolj odpornimi drevesnimi vrstami na mraznico oziroma s takimi, ki jim rastišče najbolj ustreza. Pomembno je, da je zasaditev novih dreves redkejša in da je sestava drevesnih vrst čim bolj mešana, saj tako z večjo verjetnostjo zagotovimo manj poškodb zaradi mraznice.

${ }^{1}$ Gozdarski inštitut Slovenije, Večna pot 2, 1000 Ljubljana; ${ }^{2 Z a v o d ~ z a ~ g o z d o-~}$ ve Slovenije, Območna enota Slovenj Gradec, Vorančev trg 1, 2380 Slovenj Gradec

*nikica.ogris@gozdis.si 


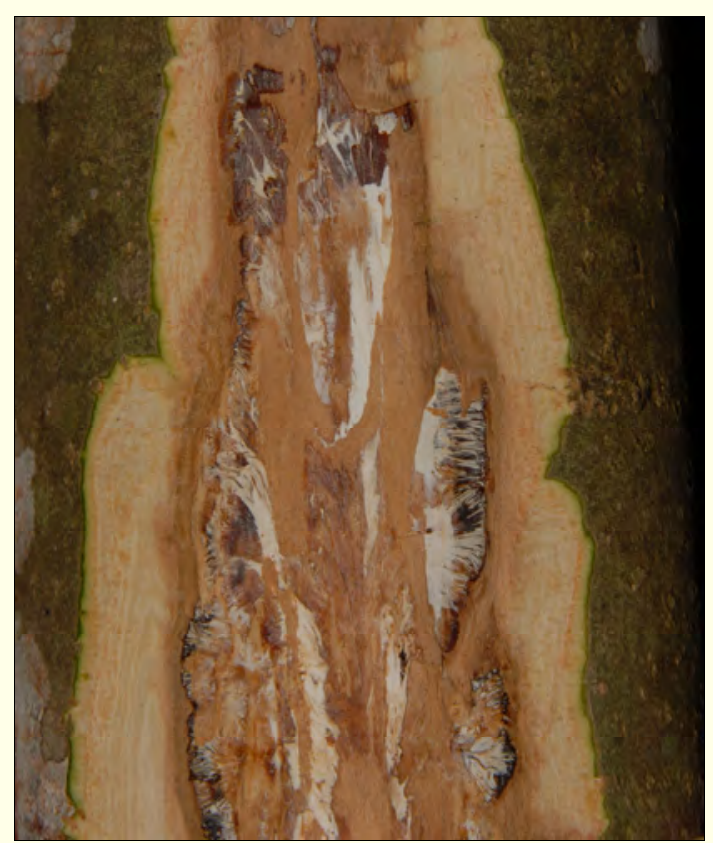

Slika 1: V skorji koreničnika velikega jesena se je razraščalo podgobje mraznice.

\section{Revno rastišče in navadno ohmelje (Loranthus europaeus) je prizadelo graden na Dularjevem bregu pri Zidanem mostu}

\section{Nikica OGRIS $^{1 *}$, Tine HAUPTMAN ${ }^{1}$, Tom LEVANIČ ${ }^{1}$, Dušan JURC ${ }^{1}$, Barbara SLABAN- JA $^{2}$, Boštjan PIHLER ${ }^{3}$}

Ob ogledu gozda na Dularjevem bregu pri Zidanem mostu smo ugotovili, da je med drevesnimi vrstami najbolj poškodovan graden (Quercus petraea). Primaren razlog za poškodovanost gradna smo pripisali revnemu, toplemu in sušnemu rastišču. Sekundaren pomen pri propadanju gradna je imelo navadno ohmelje (Loranthus europaeus). Na posameznih gradnih smo opazili tudi več kot 10 grmov navadnega ohmelja (slika 1). Bolj kakor sami grmi so bili opazni zadebeljeni predeli na vejah v obliki bul, ki so dosegale velikost človeške glave. Iz teh zadebeljenih predelov vej so izraščali grmi navadnega ohmelja, ki so imeli premer tudi do $1 \mathrm{~m}$ (slika 2). Okužene veje so se sušile in lomile. Nekateri gradni so imeli že toliko odlomljenih vej, da so bili videti kot okleščeni (slika 3).

Navadno ohmelje je 0,3-0,5 m (včasih do $1 \mathrm{~m}$ ) velik polparazitski grmiček, ki se s havstoriji vrašča $\mathrm{v}$ les svojega gostitelja in iz njega črpa vodo z mineralnimi snovmi. Na mestih, kjer ohmelje s svojimi havstoriji prodira $\mathrm{v}$ gostitelja, nastane hipertrofija tkiva oziroma odebelitev, ki ima premer do $30 \mathrm{~cm}$. Deli vej nad odebelitvami pričnejo slabeti in odmirati. Za razliko od bele omele (Viscum album), ki je polparazitska zimzelena rastlina, je ohmelje listopadni grm (bela omela ima med drugim tudi nekoliko večje in debelejše - mesnate liste, zelenorumene upogljive poganjke, večinoma bele plodove in večje število gostiteljskih rastlin kot ohmelje). Najpogostejši gostitelji ohmelja so različne vrste hrastov, pojavlja se tudi na pravem kostanju (Castanea sativa) in zelo redko na navadni bukvi (Fagus sylvatica), belem gabru (Carpinus betulus), navadni brezi (Betula pendula) (Brus, 2005; Zebec in Idžojtić, 2006; Maček, 2008). Kot omenjeno, črpa ohmelje iz gostitelja vodo in mineralne snovi. Ker je intenzivnost transpiracije polparazita pogosto večja kot intenzivnost transpiracije gostitelja, vodni potencial $\mathrm{v}$ gostitelju pade. Visoka intenzivnost transpiracije naj bi bila za polparazita nujna, saj le tako lahko dobi zadostno količino mineralnih snovi za proizvodnjo lastne biomase (Schulze in sod., 1984; Treštić in sod., 2006). Grmi ohmelja imajo zaradi tega pri oskrbi z vodo in mineralnimi snovmi prednost pred gostiteljevimi asimilacijskimi površinami, drevo zato postopoma slabi, kmalu nastopi sušni stres, postaja pa tudi vse bolj dovzetno za druge škodljive organizme, ki prodirajo skozi štrclje odlomljenih vej.

Poleg ohmelja smo na gradnu v gozdu na Dularjevem bregu opazili tudi kostanjev rak, ki ga povzroča gliva Cryphonectria parasitica (slika 4). Okužba gradna z glivo C. parasitica je bila redka. Drevesa, poškodovana zaradi navadnega ohmelja, so bila oslabljena, skozi odmrle ali odlomljene veje so jih okužile glive, predvsem tiste, ki povzročajo trohnobo lesa (npr. plutač, Phellinus sp.). Odvzeli smo vzorce vej gradna, na katerih smo določili pet vrst gliv: Colpoma quercinum, Caudospora taleola, Coryneum elevatum, Valsa inter- 